\title{
An isolable phosphaethynolato-borane and its reactivity
}

\author{
Daniel W. N. Wilson, Alexander Hinz and Jose M. Goicoechea*
}

\begin{abstract}
The synthesis and characterization of a stable phosphaethynolato-borane, $[\mathrm{B}] \mathrm{OCP} \quad(\mathbf{1},[\mathrm{B}]=\mathrm{N}, \mathrm{N}$-bis $(2,6-$ diisopropylphenyl)-2,3-dihydro-1H-1,3,2-diazaboryl), is described. The increased triple bond character of the $\mathrm{P}-\mathrm{C}$ bond in $\mathbf{1}$ relative to the free ion $\left(\mathrm{PCO}^{-}\right)$is probed in a series of reactivity studies. Compound 1 readily dimerises in donor solvents to afford a cyclic five-membered $6 \pi$-aromatic compound, cyclo- $\mathrm{P}_{2}\{\mathrm{C}[\mathrm{B}]\} \mathrm{O}\{\mathrm{CO}[\mathrm{B}]\}(\mathbf{2})$, which decarbonylates on UV irradiation. By contrast the nickelmediated dimerisation of $\mathbf{1}$ affords the isomeric diphosphacyclobutene $[\mathrm{P}(\mathrm{CO}[\mathrm{B}])]_{2}$. When $\mathbf{1}$ is reacted with organolithium reagents such as MesLi (Mes = 2,4,6-trimethylphenyl), the boryl moiety shifts and the formation of the lithoxy-borylphosphaalkene $[\mathrm{LiOC}[\mathrm{B}] \mathrm{P}(\mathrm{Mes})]_{2}$ was observed. The reactivity of this species towards electrophiles is also described.
\end{abstract}

The 2-phosphaethynolate anion, $\mathrm{PCO}^{-}$, is a phosphoruscontaining analogue of cyanate $\left(\mathrm{NCO}^{-}\right)$that has received appreciable attention as a chemical reagent over the course of the last three years. This species was first reported by Becker and co-workers in 1992, however it was the subject of limited investigation following its discovery due to difficulties associated with its manipulation..$^{[1,2]}$ Recent advances in the synthesis of the anion have reignited an interest in this remarkable species, ${ }^{[3]}$ particularly following the report of a convenient multi-gram synthesis of $\left[\mathrm{Na}\right.$ (dioxane) $\left.{ }_{x}\right][\mathrm{PCO}]$ in $2014 .{ }^{[4]}$ Since then, this compound has been extensively used as a reagent for the synthesis of a variety of novel species including phosphines and phosphorus-containing heterocycles. ${ }^{[5,6]}$ Early studies also revealed that decarbonylation of the anion allowed it to be employed as a monoatomic phosphide-transfer reagent $\left(\mathrm{P}^{-}\right){ }^{[7]}$ As with the cyanate anion, the 2-phosphaethynolate anion is ambiphilic, and capable of binding to Lewis acids via the phosphorus atom (as a phosphaketenyl moiety; Figure $1 \mathrm{~A}$ ) or via the oxygen atom (as a phosphaethynolato substituent; Figure $1 \mathrm{~B}$ ). To date, the number of examples of $\mathrm{PCO}^{-}$bonding to a metal or main group element is dominated by the former. ${ }^{[8]}$ The latter bonding mode has been proposed on a number of occasions (including for related boranes), ${ }^{\left[{ }^{[9]}\right.}$ however it has only been structurally authenticated in the coordination sphere of uranium, thorium and scandium. ${ }^{[10]}$ In principle, hard Lewis acids should favour the coordination of the anion via the oxygen atom, however even protonation of $\mathrm{PCO}^{-}$to afford the parent acid has been shown to afford the phosphorus-bonded species HPCO, ${ }^{[11]}$ as predicted by computational studies. ${ }^{[12]}$

[a] D. W. N. Wilson, Dr. A. Hinz, Prof. Dr. J. M. Goicoechea Department of Chemistry

University of Oxford

Chemistry Research Laboratory, 12 Mansfield Road, Oxford, OX1 3TA, U.K.

E-mail: jose.goicoechea@chem.ox.ac.uk

Supporting information (including experimental and analytical data) for this article is given via a link at the end of the document.

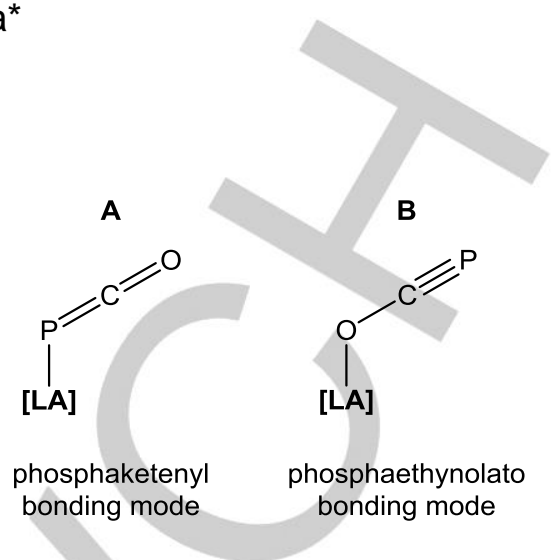

Figure 1. Two possible bonding modes of $\mathrm{PCO}^{-}$: a phosphorus-bonded phosphaketenyl (A), and an oxygen-bonded phosphaethynolate (B). The first recorded examples of each mode are for $[\mathrm{LA}]=\operatorname{Re}(\mathrm{CO})_{2}\left[\mathrm{MeC}\left(\mathrm{CH}_{2} \mathrm{PPh}_{2}\right)_{3}\right]$ and $\mathrm{M}(\text { amid })_{3}(\mathrm{M}=\mathrm{U}, \quad \mathrm{Th} ;$ amid $=\mathrm{N}, \mathrm{N}$-bis-trimethylsilyl)benzamidinate $)$, respectively. ${ }^{[8 \mathrm{a}, 10 \mathrm{a}]}$

We reasoned that in order to access a stable phosphaethynolato compound the best course of action would be to employ an electropositive main group element with strong oxophilic character. For this purpose we decided to employ a salt-metathesis strategy using the bulky bromoborane $[\mathrm{B}] \mathrm{Br}$ ( $N, N^{\prime}$-bis(2,6-diisopropylphenyl)-2-bromo-2,3-dihydro-1 H-1,3,2diazaboryl). ${ }^{[13]}$ These studies allowed us to access the first isolable 2-phosphaethynolato compound of a main group element and explore its reactivity towards a range of substrates.

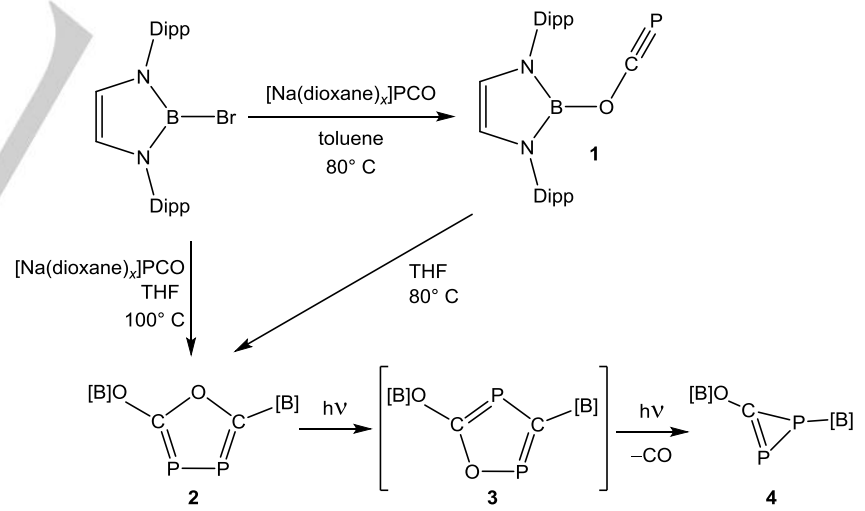

Scheme 1. Synthesis of $1-4$ by reaction of $\left.[\mathrm{Na} \text { (dioxane) })_{x}\right][\mathrm{PCO}]$ with $[\mathrm{B}] \mathrm{Br}$.

The outcome of these reactions was found to be solvent and temperature dependent. In a non-polar, non-coordinating solvent such as toluene, the reaction of $\left.[\mathrm{Na} \text { (dioxane) })_{x}\right][\mathrm{PCO}]$ with $[\mathrm{B}] \mathrm{Br}$ afforded the desired phosphaethynolato-borane (1) after several days (Scheme 1). This is evidenced by the appearance of a singlet resonance in the ${ }^{31} \mathrm{P}$ NMR spectrum of the reaction mixture at $-285.9 \mathrm{ppm}$ and of a broad resonance in the ${ }^{11} \mathrm{~B} \mathrm{NMR}$ spectrum at $19.5 \mathrm{ppm}$. The ${ }^{1} \mathrm{H}$ NMR spectrum of $\mathbf{1}$ is consistent with that of the bromoborane precursor and shows the presence of a single $[B]$ moiety. Analytically pure single crystals of the product suitable for single crystal $\mathrm{X}$-ray diffraction were obtained by crystallisation from hexane at $-30^{\circ} \mathrm{C}$ overnight. 


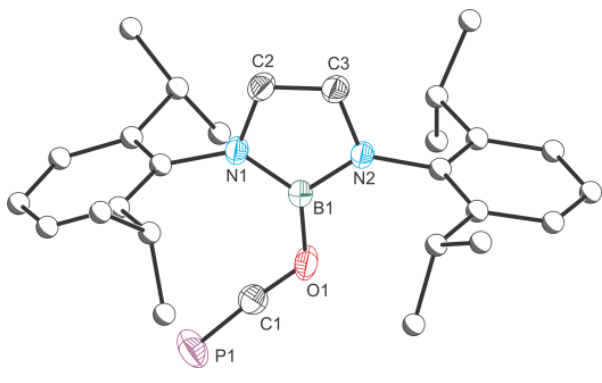

Figure 2. Molecular structure of $1{ }^{[14]}$ Anisotropic displacement ellipsoids set at $50 \%$ probability. Hydrogen atoms have been omitted for clarity. Atoms of the Dipp groups are pictured as spheres of arbitrary radius. Selected interatomic distances $[\AA]$ and angles [ $\left.{ }^{\circ}\right]$ : $\mathrm{P} 1-\mathrm{C} 1$ 1.545(2), C1-O1 1.269(2), O1-B1 1.425(2), B1-N1 1.418(2), B1-N2 1.415(2); P1-C1-O1 175.69(12), C1-O1B1 126.16(11), O1-B1-N1 129.64(12), O1-B1-N2 123.27(12), N1-B1-N2 107.09(11).

The crystal structure of $\mathbf{1}$ (Figure 2) reveals a phosphaethynolate moiety bonded to the boron centre through the oxygen atom. The most noteworthy observation is that the $\mathrm{PCO}^{-}$anion and the 1,3,2-diazaborole moiety are coplanar (mean deviation from planarity $0.0095 \AA$ ), indicating a significant degree of $p_{\pi}-p_{\pi}$ donation from the oxygen to the boron atom. This is evident in the C1-O1-B1 bond angle $\left(126.16(11)^{\circ}\right)$, and the relatively short O1-B1 distance, 1.425(2) Å, which is notably shorter than the sum of single bond covalent radii of boron and oxygen $(1.48-1.50 \AA) \cdot{ }^{[15]}$ The $\mathrm{P}-\mathrm{C}$ bond distance of the phosphaethynolate moiety, $1.545(2) \AA$, is shorter than that of free $\mathrm{PCO}^{-}(1.579(3) \AA),{ }^{[3 c]}$ indicating a significant contribution from a resonance structure with a formal $\mathrm{P} \equiv \mathrm{C}$ triple bond. Similarly the $\mathrm{C}-\mathrm{O}$ bond in $\mathbf{1}$ is longer than that recorded for $\mathrm{PCO}^{-}(1.269(2)$ and $1.212(4) \AA$, respectively). These observations are in accord with the only other known compounds exhibiting an oxygen bonded $\mathrm{PCO}^{-}$anion, namely $\mathrm{M}(\mathrm{OCP})(\mathrm{amid})_{3} \quad(\mathrm{M}=\mathrm{U}, \quad \mathrm{Th} ;$ amid $=\mathrm{N}, \mathrm{N}$-bis(trimethylsilyl)benzamidinate), $\left.\quad\left[\left\{\left({ }^{\mathrm{Ad}, \mathrm{Me}} \mathrm{ArO}\right){ }_{3} \mathrm{~N}\right)\right\} \cup(\mathrm{DME})(\mathrm{OCP})\right]$ $\left(\left\{\left({ }^{\mathrm{Ad}, \mathrm{Me}} \mathrm{ArO}\right){ }_{3} \mathrm{~N}\right\}^{3-}=\right.$ trianion of tris(2-hydroxy-3-(1-adamantyl)-5methylbenzyl)-amine), and (nacnac)Sc(OCP)(OAr)(THF) (nacnac $\left.=\left[\operatorname{ArNC}\left(\mathrm{CH}_{3}\right)\right]_{2} \mathrm{CH} ; \mathrm{Ar}=2,6-\mathrm{Pr}_{2} \mathrm{C}_{6} \mathrm{H}_{3}\right) \cdot{ }^{[10]}$ In the former of these compounds, the increased triple bond character of the $\mathrm{P}-\mathrm{C}$ interaction was demonstrated by coordinating the complexes to a $\mathrm{Ni}(\mathrm{COD})$ moiety (COD $=1,5$-cyclooctadiene). It is noteworthy, that phosphaalkyne $\mathbf{1}$ is thermodynamically less stable by $28 \mathrm{~kJ} \mathrm{~mol}^{-1}$ than the isomeric phosphaketene, but no viable monomolecular isomerisation pathway could be elucidated computationally. This is consistent with the observation that no isomerisation of $\mathbf{1}$ is observed upon heating. Intermolecular isomerisation pathways are viable and were computed (see SI for details).

Compound $\mathbf{1}$ was found to dimerise in polar donor solvents such as THF. This is evident by the appearance of an $A B$ spin system in the ${ }^{31} \mathrm{P}$ NMR spectrum of the reaction mixture consisting of two doublets at 223.3 and $38.3 \mathrm{ppm}$ with a ${ }^{1} J_{\mathrm{P}-\mathrm{P}}$ coupling constant of $386 \mathrm{~Hz}$. The ${ }^{1} \mathrm{H}$ NMR spectrum of the resulting product reveals the evidence of two chemically distinct 1,3,2-diazaborole moieties.
Single crystals of the resulting product reveal a dimeric form of 1 with a direct $\mathrm{P}-\mathrm{P}$ bond, cyclo- $\mathrm{P}_{2}\{\mathrm{C}[\mathrm{B}]\} \mathrm{O}\{\mathrm{CO}[\mathrm{B}]\}$ (2, Figure 3). This species is a five-membered 1,3,4-oxadiphosphole, in which one of the 1,3,2-diazaborole moieties of the phosphaethynolatoborane precursor has migrated from an oxygen to a carbon atom. ${ }^{[16]}$ The planar $\mathrm{P}_{2} \mathrm{C}_{2} \mathrm{O}$ core is a $6 \pi$ electron system which exhibits aromaticity with NICS(0) and NICS(1) values of -10.1 and $-11.5 \mathrm{ppm}$, respectively. It is worth noting that this oligomerization contrasts with that previously observed for compounds of $\mathrm{PCO}^{-}$with boranes, presumably due to differences in the steric profiles of the substituents. ${ }^{[9 b, 17]}$

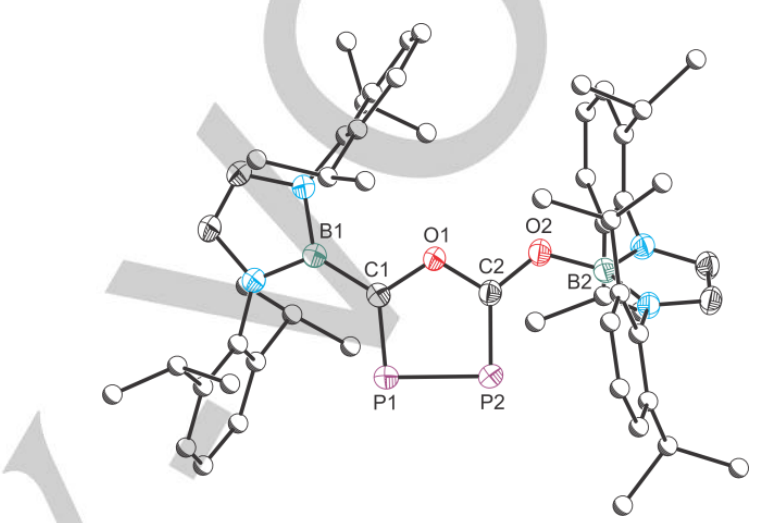

Figure 3. Molecular structure of 2. Anisotropic displacement ellipsoids set at $50 \%$ probability. Hydrogen atoms have been omitted for clarity. Atoms of the Dipp groups are pictured as spheres of arbitrary radius. Selected interatomic distances [Å]: P1-P2 2.143(1), P1-C1 1.703(2), C1-O1 1.374(2), C1-B1 1.550(2), O1-C2 1.340(2), C2-O2 1.328(2), O2-B2 1.398(2), C2-P2 1.721(2).

Photolysis of solutions of 2 results in the decarbonylation of the 1,3,4-oxadiphosphole to afford a $1 \mathrm{H}$-diphosphirene, cyclo$\mathrm{P}\{\mathrm{PO}[\mathrm{B}])\{\mathrm{C}[\mathrm{B}]\}$ (4). There are only two known isolable $1 \mathrm{H}$ diphosphirenes, the first of which was reported by Niecke in $1989,{ }^{[18]}$ and since then only a handful of examples of these species have been synthesised in the coordination sphere of metals or as diphosphirenium salts. ${ }^{[19,20]}$ The ${ }^{31} \mathrm{P}$ NMR spectrum of 4 exhibits two doublet resonances at 284.6 and $-71.5 \mathrm{ppm}$ $\left({ }^{1} \mathrm{JP}_{\mathrm{P}}=188 \mathrm{~Hz}\right)$ which differ somewhat to the two other known $1 \mathrm{H}$-diphosphirenes (cyclo- $\mathrm{P}\left\{\mathrm{PN}\left({ }^{\mathrm{P}} \mathrm{Pr}\right)_{2}\right\}\left\{\mathrm{CN}(\mathrm{Pr})\left(\mathrm{SiMe}_{3}\right)\right\}: 14.9$ and $-118.7 \mathrm{ppm}\left({ }^{1} \mathrm{JP}_{\mathrm{P}-\mathrm{P}}=104 \mathrm{~Hz}\right)$; and cyclo-P $\left\{\mathrm{PN}\left({ }^{\mathrm{P}} \mathrm{Pr}\right)_{2}\right\}\left\{\mathrm{CN}\left({ }^{(\mathrm{Pr}}\right)_{2}\right\}$ : -23.7 and $\left.-121.7 \mathrm{ppm}\left({ }^{1} \mathrm{~J}_{\mathrm{P}-\mathrm{P}}=121 \mathrm{~Hz}\right)\right)$, however the values are in good agreement with the computed shifts of +298 and -79 ppm. The greatest difference in chemical shift is observed for the $\sigma^{2}$-phosphorus atom ( $P 1$ in Figure 4) which is a consequence of the ability of the boryl functionality to accept $\pi$ electron density from the diphosphirene core, contrasting with the two previously reported systems where the amide functionalities act as $\pi$ electron donors.

An intermediate species during the photolysis experiments could also be observed, as well as temporary colour change to green. The intermediate eluded isolation, but was characterised by multinuclear NMR spectroscopy. All attempts to isolate single crystals suitable for X-ray analysis for this compound were unsuccessful. Computationally, various possible products of photolysis were investigated and the best agreement with the observed spectroscopic data $\left(\delta\left({ }^{31} \mathrm{P}\right): 53.7,319.0 \mathrm{ppm},{ }^{2} \mathrm{~J}_{\mathrm{P}-\mathrm{P}}=7\right.$ 
$\mathrm{Hz}$; calc. 55, $314 \mathrm{ppm}$ ) was found for the cyclopentadiene derivative cyclo-PO $\{\mathrm{CO}[\mathrm{B}]\} \mathrm{P}\{\mathrm{C}[\mathrm{B}]\} \quad(3$, Scheme 1$)$, which is thermally more stable than 2 by $30 \mathrm{~kJ} \mathrm{~mol}^{-1}$.

The molecular structure of 4 (Figure 4) reveals a triatomic cyclic core with a P-P bond of 2.173(1) $\AA$ (in line with a P-P single bond) and two notably different $\mathrm{P}-\mathrm{C}$ bonds with interatomic distances of $1.802(2)$ and $1.670(2) \AA$, consistent with a $\mathrm{P}-\mathrm{C}$ single and double bond, respectively (the sum of covalent radii for $\mathrm{P}-\mathrm{C}$ and $\mathrm{P}=\mathrm{C}$ bonds are 1.86 and $1.69 \AA) .{ }^{[15 a, 15 b]}$ The C-B bond present in 4 is $1.534(3) \AA$ (comparable to that observed for compound 2, 1.550(2) $\AA$ ), and indicates some degree of multiple bond character, in line with the $\pi$-donation from carbon to the boron atom.

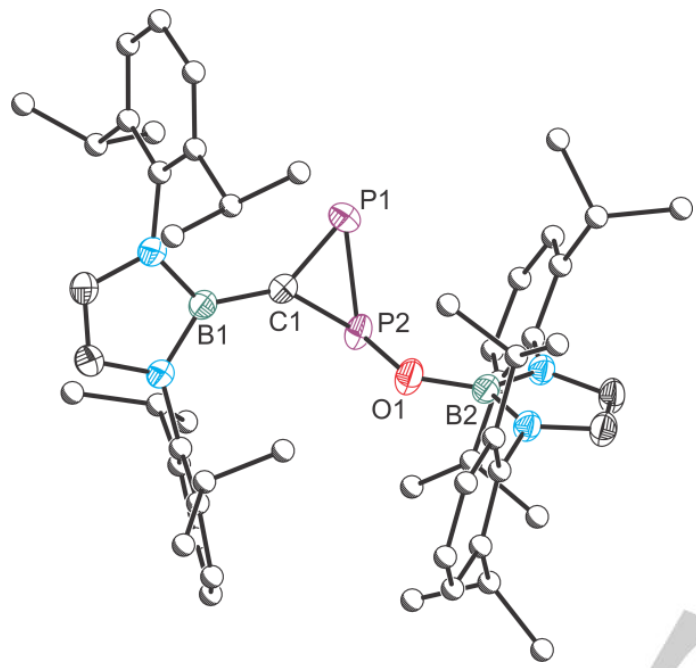

Figure 4. Molecular structure of $\mathbf{4}$ (major component of the positionally disordered molecule pictured). Anisotropic displacement ellipsoids set at $50 \%$ probability. Hydrogen atoms have been omitted for clarity. Atoms of the Dipp groups are pictured as spheres of arbitrary radius. Selected interatomic distances $[\AA \AA]$ and angles $\left[^{\circ}\right]$ : P1-C1 1.670(2), P1-P2 2.173(1), C1-B1 1.534(3), C1-P2 1.802(2), P2-O1 1.670(2), O1-B2 1.381(2); B1-C1-P1 141.06(14), B1-C1-P2 141.02(13), C1-P1-P2 54.03(6), C1-P2-P1 48.59(5), P1-C1-P2 77.38(8), C1-P2-O1 103.44(8), P1-P2-O1 104.85(6).

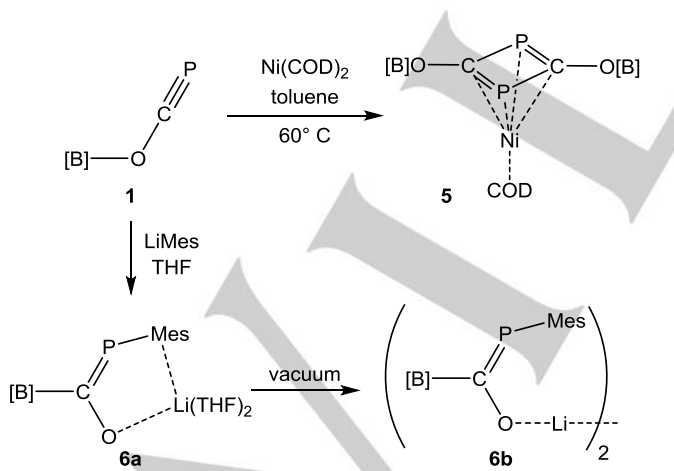

Scheme 2. Synthesis of 5 and $\mathbf{6 a} / \mathbf{b}$ by reaction of $[\mathrm{B}] \mathrm{OCP}$ with $\left[\mathrm{Ni}(\mathrm{COD})_{2}\right]$ and LiMes (Mes = 2,4,6-trimetylphenyl), respectively.

A different pathway for the oligomerisation of $[\mathrm{B}] \mathrm{OCP}$ (1) was found when it was treated with $\mathrm{Ni}(\mathrm{COD})_{2}$ (Scheme 2). A nickel-mediated dimerization was observed on reacting 1 with 0.5 equivalents of $\mathrm{Ni}(\mathrm{COD})_{2}$ to cleanly afford
(COD)Ni[P(CO[B] $]_{2}(5)$. The ${ }^{31} \mathrm{P}$ NMR resonance of this species was observed at $45.7 \mathrm{ppm}$ (calc. $35 \mathrm{ppm}$ ). Structurally, the nickel complex is characterised by a slightly bent $[\mathrm{P}(\mathrm{CO}[\mathrm{B}])]_{2}$ moiety (dihedral CPPC angle $170.8(2)^{\circ}$, Figure 5 ). The sum of bond angles at the carbon atom equals $359.9^{\circ}$ which indicates a planar environment for the $\mathrm{C}$ atom. The $\mathrm{P}-\mathrm{C}$ bond lengths amount to $1.803(2)$ and $1.814(2) \AA$, while the $\mathrm{C}-\mathrm{O}$ bond length is $1.365(2)$ and the P...P distance is $2.858(1) \AA$ (Figure 5).

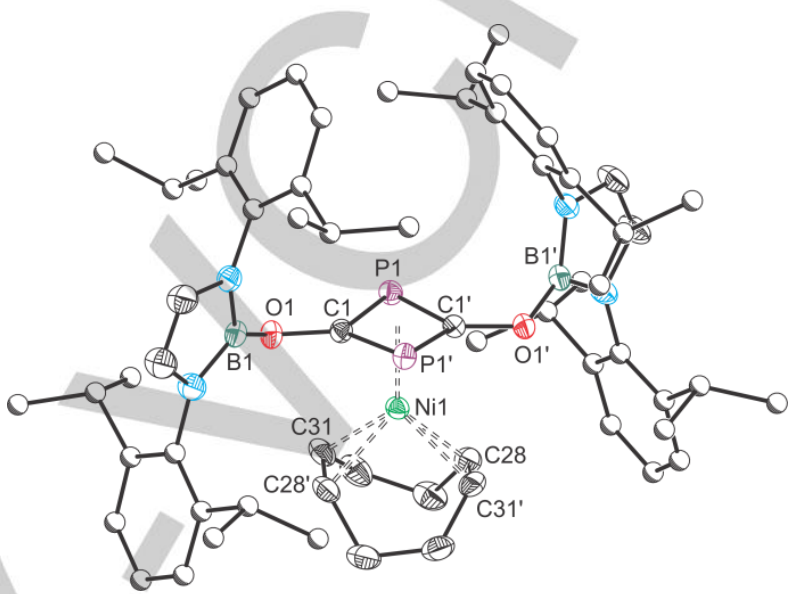

Figure 5. Molecular structure of 5. Anisotropic displacement ellipsoids set at $50 \%$ probability. Hydrogen atoms have been omitted for clarity. Atoms of the Dipp groups are pictured as spheres of arbitrary radius. Selected interatomic distances [Å] and angles [ $\left.{ }^{\circ}\right]$ : Ni1-P1 2.3032(5), P1-C1' 1.8036(17), P1-C1 1.8141(17), O1-C1 1.365(2), O1-B1 1.391(2); C1-O1-B1 122.56(14), C1P1-C1' 75.34(9), P1-Ni1-P1' 76.70(2), O1-C1-P1' 129.48(13), O1-C1-P1 126.03(13). Symmetry operation ': $1-x, 1-y, 0.5-z$.

Treatment of 1 with mesityllithium in $\mathrm{C}_{6} \mathrm{D}_{6}$ (with a small amount of THF to aid dissolution) reveals clean conversion to a product with a singlet resonance in the ${ }^{31} \mathrm{P}$ NMR spectrum at $107.1 \mathrm{ppm}$ (Scheme 2). The ${ }^{1} \mathrm{H}$ NMR spectrum of the resulting species is consistent with the presence of a single boryl moiety and a mesityl functionality. The compound was crystallised from a THF solution and identified as $\left[(\mathrm{THF})_{2} \mathrm{LiOC}[\mathrm{B}] \mathrm{P}(\mathrm{Mes})\right](\mathbf{6 a})$, however all of the crystals obtained were poorly diffracting and a satisfactory crystal structure could not be obtained. Treatment of a solid sample of $\mathbf{6 a}$ under a dynamic vacuum allowed complete removal of THF and dissolution of the resulting solid in $\mathrm{C}_{6} \mathrm{D}_{6}$ revealed a downfield shift of the ${ }^{31} \mathrm{P}$ NMR resonance from 107.1 to $136.7 \mathrm{ppm}$. From this solution the dimeric species $[\mathrm{LiOC}[\mathrm{B}] \mathrm{P}(\mathrm{Mes})]_{2}$ (6b) could be isolated (Figure 6). The averaged bond metrics reveal CO distances of $1.320 \AA, P=C$ distances along the phosphaalkene unit of $1.726 \AA$, contrasted by the $\mathrm{P}-\mathrm{C}$ single bond lengths $1.845 \AA$ and short $\mathrm{O} \cdots \mathrm{Li}$ contacts of $1.871 \AA$. The dimer [LiOC[B]P(Mes) $]_{2}$ (6b) can be cleaved into monomers by addition of a sequestering agent such as 12-crown-4 to give [(12-crown-4)LiOC[B]P(Mes)] (6c; see SI).

Furthermore, the $[\mathrm{LiOC}[\mathrm{B}] \mathrm{P}(\mathrm{Mes})]_{2}(\mathbf{6 b})$ can be treated with stoichiometric amounts of water to initially afford [HOC[B]P(Mes)] (Scheme 3, 7a). Its solid state structure (Figure 7, left) reveals a short $\mathrm{P} 1-\mathrm{C} 1$ double bond $(1.699(2) \AA$ ) and a longer P1-C28 single bond (1.856(2) $\AA$ ). This hydroxy-borylphosphaalkene can only be isolated as pure compound if the workup is completed rapidly. In solution, there is an equilibrium 
between the hydroxy-phosphaalkene $[\mathrm{HOC}[\mathrm{B}] \mathrm{P}(\mathrm{Mes})](7 \mathrm{a})$ and its tautomeric acyl-phosphine $[\mathrm{OC}[\mathrm{B}] \mathrm{P}(\mathrm{Mes}) \mathrm{H}](\mathbf{7 b})$ which is dependent on the polarity of the solvent. Both isomers can be easily distinguished by their ${ }^{31} \mathrm{P}$ NMR resonances, with $7 \mathrm{a}$ at 147.5 (calc. $141 \mathrm{ppm}$ ) and $7 \mathrm{~b}$ at $-29.0 \mathrm{ppm}\left({ }^{1} \mathrm{JP}_{\mathrm{P}-\mathrm{H}}=236 \mathrm{~Hz}\right.$; calc $\left.\delta\left({ }^{31} \mathrm{P}\right):-17 \mathrm{ppm}\right)$. Calculations for the gas phase predict the phosphine $7 \mathrm{~b}$ to be more stable than phosphaalkene $7 \mathrm{a}$ by only $2.8 \mathrm{~kJ} \mathrm{~mol}^{-1}$ which falls nicely in line with the observation of a solvent-dependent equilibrium in solution.

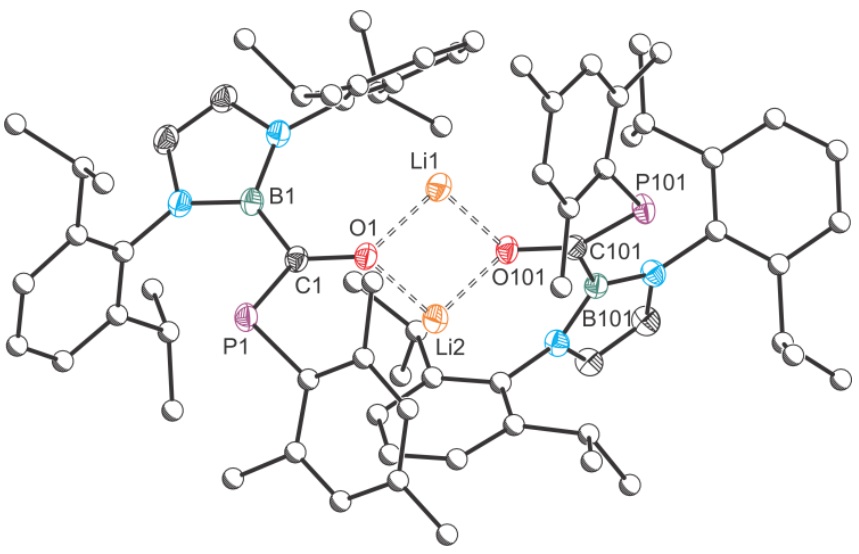

Figure 6. Molecular structure of one of the two crystallographically unique molecules of $\mathbf{6 b}$ present in $\mathbf{6 b} \cdot 0.75 \mathrm{hex}$. Anisotropic displacement ellipsoids set at $50 \%$ probability. Hydrogen atoms and solvent of crystallisation have been omitted for clarity. Atoms of the aryl groups are pictured as spheres of arbitrary radius. Selected interatomic distances $[\AA]$ and angles $\left[{ }^{\circ}\right]$ : P1-C1 1.732(2), C1-

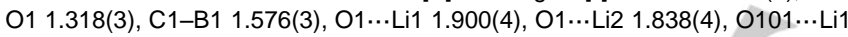

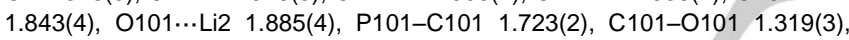
C101-B101 1.586(3); P1-C1-B1 114.06(14), P1-C1-O1 128.92(16), B1-C1O1 117.01(17), P101-C101-B101 115.14(14), P101-C101-O101 128.71(16), B101-C101-O101 116.14(18).

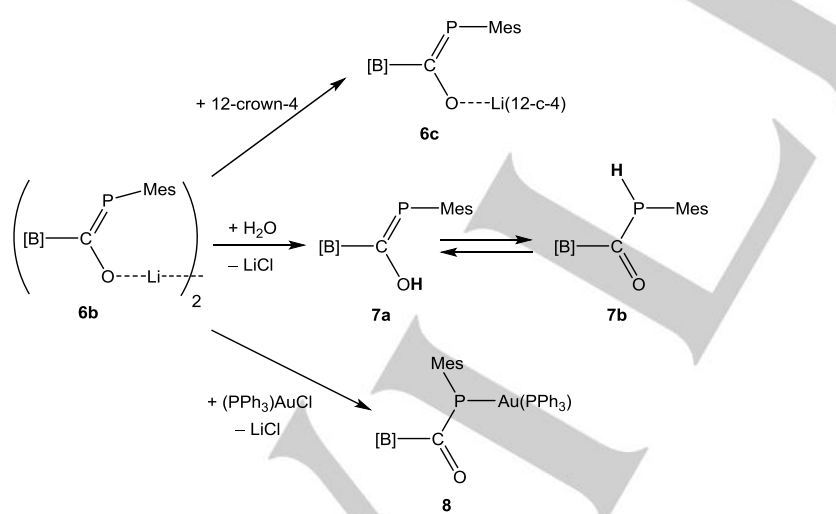

Scheme 3. Reactivity of $\mathbf{6 b}$ towards 12 -crown-4, water and a gold complex.

To study the reactivity of $\mathbf{6 b}$ towards a softer electrophile, $\left(\mathrm{PPh}_{3}\right) \mathrm{AuCl}$ was employed (Scheme 3). After elimination of $\mathrm{LiCl}$, the gold complex [OC[B]P(Mes) $\left.\mathrm{Au}\left(\mathrm{PPh}_{3}\right)\right](8)$ was obtained. In this acylphosphanido complex, the gold atom adopts the expected linear coordination mode (P-Au-P 175.86(3) ${ }^{\circ}$; Figure 7 , right) and a slightly longer $\mathrm{Au}-\mathrm{P}$ bond to the anionic substituent (Au1-P1 2.330(1), Au1-P2 2.307(1) Å). Within the acylphosphanido moiety, the $\mathrm{P}-\mathrm{C}$ bonds are of equal length (P1-C1 1.832(4), P1-C28 1.850(4) Å). In the ${ }^{31} \mathrm{P}$ NMR spectrum, the compound features an $A B$ spin system with resonances at 50.3 and $44.0 \mathrm{ppm}\left({ }^{2} \mathrm{~J}_{\mathrm{P}-\mathrm{P}}=145 \mathrm{~Hz}\right)$.

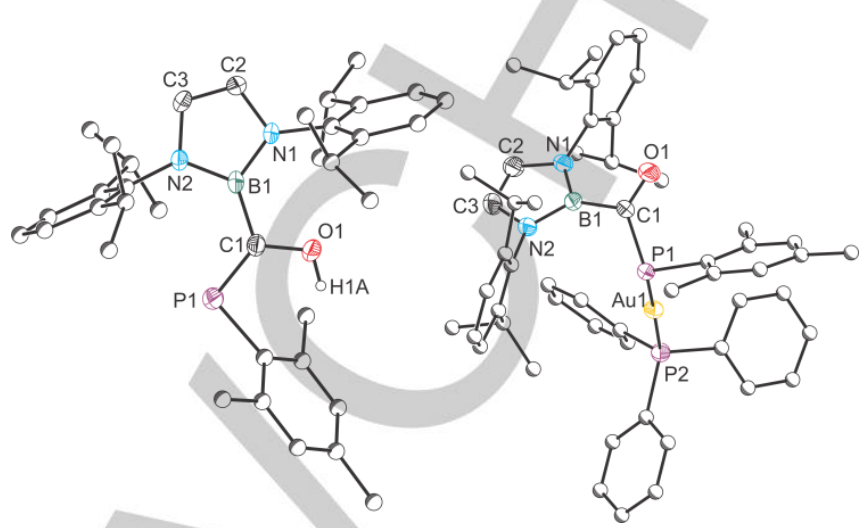

Figure 7. Molecular structurea of 7a (left) and 8 (right). Anisotropic displacement ellipsoids set at $50 \%$ probability. Hydrogen atoms have been omitted for clarity. Atoms of the aryl groups are pictured as spheres of arbitrary radius. Selected interatomic distances $[\AA \AA]$ and angles $\left[^{\circ}\right]$ : 7a: $\left[^{\circ}\right]$ : $\mathrm{P} 1-\mathrm{C} 1$ 1.699(2), P1-C28 1.856(2), N1-C2 1.400(3), B1-C1 1.573(3), O1-C1 1.352(3); C1-P1-C28 100.71(10), O1-C1-P1 125.18(17). 8: Au1-P2 2.307(1), Au1-P1 2.330(1), P1-C1 1.832(4), P1-C28 1.850(4), O1-C1 1.233(5); P2Au1-P1 175.86(3), C1-P1-C28 103.29(16), O1-C1-P1 122.2(3).

We have demonstrated the synthesis of the first stable oxygen-bonded phosphaethynolate compound of a main group element and investigated its reactivity. In polar media, dimerisation occurs to afford five-membered heterocycles, which can be photolytically decarbonylated to form a rare example of a diphosphirene. Contrasting this behaviour, in nickel-templated dimerisations a four-membered $\mathrm{C}_{2} \mathrm{P}_{2}$ heterocycle was obtained. The phosphaethynolato-borane also reacts with organolithium species to give lithoxy-boryl-phosphaalkenes which are versatile starting materials for further conversions.

\section{Acknowledgements}

We thank the EPSRC and the University of Oxford for financial support of this research (EP/M027732/1 and DTA studentship D.W.N.W.) and the University of Oxford for access to Chemical Crystallography and Advanced Research Computing (ARC) facilities (http://dx.doi.org/10.5281/zenodo.22558). We also thank Elemental Microanalysis Ltd. (Devon) for performing the elemental analyses.

Keywords: 2 -phosphaethynolate $\cdot 1 \mathrm{H}$-diphosphirene $\bullet$ phosphalkenes $\cdot 1,3,2$-diazaborole $\cdot$ phosphorus

[1] G. Becker, W. Schwarz, N. Seidler, M. Westerhausen, Z. Anorg. Allg. Chem. 1992, 612, 72-82.

[2] (a) G. Becker, G. Heckmann, K. Hübler, W. Schwarz, Z. Anorg. Allg. Chem. 1995, 621, 34-46; (b) G. Becker, K. Hübler, M. Niemeyer, N. Seidler, B. Thinus, Z. Anorg. Allg. Chem. 1996, 622, 197-211; (c) M. 
Westerhausen, S. Schneiderbauer, H. Piotrowski, M. Suter, H. Nöth, J. Organomet. Chem. 2002, 643-644, 189-193.

[3] (a) F. F. Puschmann, D. Stein, D. Heift, C. Hendriksen, Z. A. Gal, H.-F. Grützmacher, H. Grützmacher, Angew. Chem. Int. Ed. 2011, 50, 84208423; (b) I. Krummenacher, C. C. Cummins, Polyhedron 2012, 32, 10-13; (c) A. R. Jupp, J. M. Goicoechea, Angew. Chem. Int. Ed. 2013 52, 10064-10067.

[4] D. Heift, Z. Benkő, H. Grützmacher, Dalton Trans. 2014, 43, 831-840.

[5] (a) A. R. Jupp, J. M. Goicoechea, J. Am. Chem. Soc. 2013, 135, 19131-19134; (b) M. B. Geeson, A. R. Jupp, J. E. McGrady, J. M. Goicoechea, Chem. Commun. 2014, 50, 12281-12284; (c) A. R. Jupp G. Trott, É. Payen de la Garanderie, J. D. G. Holl, D. Carmichael, J. M. Goicoechea, Chem. Eur. J. 2015, 21, 8015-8018.

[6] (a) X. Chen, S. Alidori, F. F. Puschmann, G. Santiso-Quinones, Z Benkő, Z. Li, G. Becker, H.-F. Grützmacher, H. Grützmacher, Angew. Chem. Int. Ed. 2014, 53, 1641-1645. (b) D. Heift, Z. Benkő, H Grützmacher, Angew. Chem. Int. Ed. 2014, 53, 6757-6761; (c) D. Heift, Z. Benkö, H. Grützmacher, Chem. Eur. J. 2014, 20, 11326-11330; (d) T. P. Robinson, J. M. Goicoechea, Chem. Eur. J. 2015, 21, 5727-5731; (e) Z. Li, X. Chen, M. Bergeler, M. Reiher, C. Su, H. Grützmacher, Dalton Trans. 2015, 44, 6431-6438; (e) R. Suter, Z. Benkő, H Grützmacher, Chem. Eur. J. 2016, 22, 14979-14987.

[7] (a) D. Heift, Z. Benkö, H. Grützmacher, A. R. Jupp, J. M. Goicoechea, Chem. Sci. 2015, 6, 4017-4024; (b) A. M. Tondreau, Z. Benkö, J. R Harmer, H. Grützmacher, Chem. Sci. 2014, 5, 1545-1554; (c) T. P. Robinson, M. J. Cowley, D. Scheschkewitz, J. M. Goicoechea, Angew. Chem. Int. Ed. 2015, 54, 683-686.

[8] (a) S. Alidori, D. Heift, G. Santiso-Quinones, Z. Benkő, H. Grützmacher, M. Caporali, L. Gonsalvi, A. Rossin, M. Peruzzini, Chem. Eur. J. 2012 18, 14805-14811; (b) L. Liu, D. A. Ruiz, F. Dahcheh, G. Bertrand, R Suter, A. M. Tondreau, H. Grützmacher, Chem. Sci. 2016, 7, 23352341; (c) A. R. Jupp, M. B. Geeson, J. E. McGrady, J. M. Goicoechea Eur. J. Inorg. Chem. 2016, 639-648; (d) S. Yao, Y. Xiong, T. Szilvási, H. Grützmacher, M. Driess, Angew. Chem. Int. Ed. 2016, 55, 4781-4785; (e) Y. Wu, L. Liu, J. Su, J. Zhu, Z. Ji, Y. Zhao, Organometallics 2016 35, 1593-1596; (f) N. Del Rio, A. Baceiredo, N. Saffon-Merceron, D. Hashizume, D. Lutters, T. Müller, T. Kato, Angew. Chem. Int. Ed. 2016 55, 4753 -4758; (g) L. Liu, D. A. Ruiz, D. Munz, G. Bertrand, Chem 2016, 1, 147-153; (h) M. M. Hansmann, R. Jazzar, G. Bertrand, J. Am Chem. Soc. 2016, 138, 8356-8359; (i) Z. Li, X. Chen, Z. Benkö, L. Liu, D. A. Ruiz, J. L. Peltier, G. Bertrand, C.-Y. Su, H. Grützmacher, Angew. Chem. Int. Ed. 2016, 55, 6018-6022; (j) Y. Xiong, S. Yao, T. Szilvási, E. Ballestero-Martínez, H. Grützmacher, M. Driess, Angew. Chem. Int. Ed. 2017, 56, 4333-4336; (k) Z. Li, X. Chen, D. M. Andrada, G. Frenking, Z Benkő, Y. Li, J. R. Harmer, C.-Y. Su, H. Grützmacher, Angew. Chem. Int. Ed. 2017, 56, 5744-5749.

[9] (a) D. Heift, Z. Benkő, H. Grützmacher, Dalton Trans. 2014, 43, 5920 5928; (b) R. Suter, Y. Mei, M. Baker, Z. Benkö, Z. Li, H. Grützmacher, Angew. Chem. Int. Ed. 2017, 56, 1356-1360.

[10] (a) C. Camp, N. Settineri, J. Lefèvre, A. R. Jupp, J. M. Goicoechea, L. Maron, J. Arnold, Chem. Sci. 2015, 2, 6379-6384; (b) C. J. Hoerger, F. W. Heinemann, E. Louyriac, L. Maron, H. Grützmacher, K. Meyer, Organometallics 2017, 36, 4351-4354; (c) L. N. Grant, B. Pinter, B. C
Manor, H. Grützmacher, D. J. Mindiola, Angew. Chem. Int. Ed. DOI: 10.1002/anie.201710757.

[11] A. Hinz, R. Labbow, C. Rennick, A. Schulz, J. M. Goicoechea, Angew. Chem. Int. Ed. 2017, 56, 3911-3915.

[12] (a) M. T. Nguyen, A. F. Hegarty, M. A. McGinn, P. Ruelle, J. Chem. Soc., Perkin Trans. 2 1985, 1991-1997; (b) M. T. Nguyen, P. Ruelle, J. Chem. Soc. Faraday Trans. 2 1984, 80, 1225-1234; (c) M. Lattelais, F. Pauzat, J. Pilmé, Y. Ellinger, Phys. Chem. Chem. Phys. 2008, 10, 2089-2097; (d) X. Cheng, Y. Zhao, L. Li, X. Tao, J. Mol. Struct. THEOCHEM 2004, 682, 137-143; (e) H. Fu, H. Yu, Y. Chi, Z. Li, X.-R Huang, C.-C. Sun, Chem. Phys. Lett. 2002, 361, 62-70; (f) G. von Frantzius, A. Espinosa Ferao, R. Streubel, Chem. Sci. 2013, 4, 43094322.

[13] Y. Segawa, M. Yamashita, K. Nozaki, Science 2006, 314, 113-115.

[14] CCDC 1589990-1589997 contain the supplementary crystallographic data for this paper. These data are provided free of charge by The Cambridge Crystallographic Data Centre.

[15] (a) P. Pyykkö, M. Atsumi, Chem. Eur. J. 2009, 15, 186-197; (b) P. Pyykkö, M. Atsumi, Chem. Eur. J. 2009, 15, 12770-12779; (c) B. Cordero, V. Gómez, A. E. Platero-Prats, M. Revés, J. Echeverría, E. Cremades, F. Barragán, S. Alvarez, Dalton Trans. 2008, 2832-2838.

[16] Related neutral and anionic five membered heterocycles include reference $6 \mathrm{a}$ and: (a) A. Mack, U. Bergsträßer, G. J. Reiß, M. Regitz, Eur. J. Org. Chem. 1999, 587-595; (b) S. Weidner, J. Renner, U. Bergsträßer, M. Regitz, H. Heydt, Synthesis 2004, 241-248; (c) S. J Collier, Sci. Synth. 2004, 659-687; (d) A. S. Ionkin, W. J. Marshall, B. M. Fish, M. F. Schiffhauer, F. Davidson, C. N. McEwen, Organometallics 2009, 28, 2410-2416; (e) D. Heift, Z. Benkö, R. Suter, R. Verela, H. Grützmacher, Chem. Sci. 2016, 7, 6125-6131; (f) M. M. Hansmann, D. A. Ruiz, L. Liu, R. Jazzar, G. Bertrand, Chem. Sci. 2017 8, 3720-3725. (g) R. J. Gilliard, R. Suter, E. Schrader, Z. Benkö, A. L. Rheingold, H. Grützmacher, J. D. Protasiewicz, Chem. Commun. 2017 53, 12325-12328

[17] K. M. Szkop, A. R. Jupp, R. Suter, H. Grützmacher, D. W. Stephan, Angew. Chem. Int. Ed. 2017, 56, 14174-14177.

[18] (a) E. Niecke, R. Streubel, M. Nieger, D. Stalke, Angew. Chem. Int. Ed. Engl. 1989, 28, 1673-1674; (b) D. Bourissou, Y. Canac, M. I. Collado, A. Baceiredo, G. Bertrand, Chem. Commun. 1997, 2399-2400.

[19] (a) F. Mercier, L. Ricard, F. Mathey, M. Regitz, J. Chem. Soc., Chem. Commun. 1991, 1305-1307; (b) R. Streubel, L. Ernst, J. Jeske, P. G. Jones, J. Chem. Soc., Chem. Commun. 1995, 2113-2114; (c) D. Bourissou, Y. Canac, M. I. Collado, A. Baceiredo, G. Bertrand, J. Am Chem. Soc. 1997, 119, 9923-9924; (d) D. Bourissou, Y. Canac, H. Gornitzka, C. J. Marsden, A. Baceiredo, G. Bertrand, G. Eur. J. Inorg. Chem. 1999, 1479-1488.

[20] (a) F. Castan, A. Baceiredo, J. Fischer, A. De Cian, G. Commenges, G Bertrand, J. Am. Chem. Soc. 1991, 113, 8160-8161; (b) M Soleilhavoup, Y. Canac, A. M. Polozov, A. Baceiredo, G. Bertrand, J. Am. Chem. Soc. 1994, 116, 6149-6152; (c) M. Soleilhavoup, A Baceiredo, F. Dahan, G. Bertrand, J. Chem. Soc., Chem. Commun. 1994, 337-338; (c) Y. Canac, M. Soleilhavoup, L. Ricard, A. Baceiredo G. Bertrand, Organometallics 1995, 14, 3614-3116; (d) Y. Canac, A Baceiredo, W. W. Schoeller, D. Gigmes, G. Bertrand, J. Am. Chem. Soc. 1997, 119, 7579. 
Entry for the Table of Contents (Please choose one layout)

Layout 1:

\section{COMMUNICATION}

The synthesis, characterization and reactivity of a stable

phosphaethynolato-borane, [B]OCP $(\mathbf{1},[\mathrm{B}]=N, N$-bis $(2,6$ -

diisopropylphenyl)-2,3-dihydro- $1 \mathrm{H}$ $1,3,2$-diazaboryl), is described.

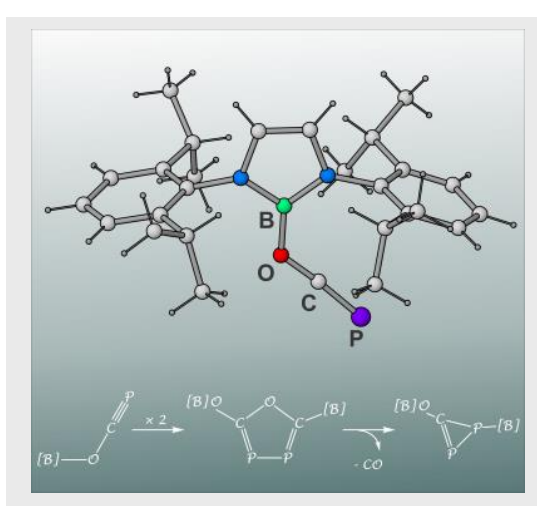

Daniel W. N. Wilson, Alexander Hinz and Jose M. Goicoechea*

Page No. - Page No.

An isolable phosphaethynolatoborane and its reactivity 